\title{
Irreplaceability and Unique Value
}

Christopher Grau

Florida International University

"The Missyplicity Project" is the name of a 2.3-million-dollar research project being undertaken at the University of Texas in the hopes of successfully cloning a dog named "Missy." The wealthy owners of this dog, who wish to remain anonymous, acknowledge that the cloned dog will not be Missy, but they seem to think that she will be the next best thing. The explicit goal of the project is to come as close as possible to creating an exact duplicate of Missy, so that after Missy has passed on they can continue to love what was so lovable about Missy as manifested in this new dog. ${ }^{1}$

Both the family that owns Missy and the University of Texas have come under attack for pursuing Missyplicity. The attacks have been varied but in general they come in two distinct (though related) varieties: (1) The family is being excessively sentimental in their attachment to a particular pet and they should simply "get over it." (2) The money being devoted to the project is being foolishly spent when it could instead be used to support animal shelters, research into prevention of animal diseases, or countless other projects that would clearly benefit animals and/or humans.

I am inclined to agree with the second kind of criticism, but I object to the first, though I suspect for reasons that Missy's family would not share. Rather than this being a case of excessive sentimentality, it seems to me that part of what makes the Missyplicity project problematic is that the owners of Missy aren't being nearly sentimental enough in their attachment to Missy. 
Indeed, there is an important sense in which they arguably aren't attached to Missy at all. After all, everyone involved agrees that Missy is not going to continue living as a result of this project. What will possibly be achieved is the creation of a duplicate of Missy who will share Missy's physical and behavioral characteristics.

If Missy were capable of understanding the Missyplicity project and also capable of communicating her opinion on the matter, it is entirely understandable that she might well bark out a fierce objection to the whole affair. Her response might go something like this:

Look people, I don't doubt that you (in a sense) care for me and wish me well. I appreciate the wonderful treatment I've received over the years and I know you will be saddened when in fact I do reach the end of my life. However, this project to clone me is at best somewhat misguided and at worst horribly creepy. While it is difficult (especially for me) to put into words exactly what is so objectionable about the whole thing, part of what bothers me is that it raises the suspicion that you haven't really loved me all these years after all. Sure, you loved my shiny coat, my playful disposition, and even my stubborn refusal to come when called, but loving all these characteristics of mine isn't the same as truly loving me. If your love could be so easily transferred to another dog with the same characteristics, I can't help but feel that there is a way in which I am not being appreciated as an individual, but simply as a creature that happens to possess those dog properties that you really care about.

While I can't blame you for liking my properties, as I'm pretty fond of them myself, I do feel that somehow something has been left behind in your love. Namely, me, Missy. I am not simply a collection of properties. After all, I've changed over the years, and your love remained, or at least appeared to remain, constant. I used to have a mangy coat, an annoyingly hyperactive personality, and a tendency toward incontinence (and I don't mean that in the philosophical sense of the term) and yet you loved me still. Why, then, are you so eager to transfer your love for me to a duplicate dog who happens to have (if your project is successful) the same properties I now possess? Can you blame me for feeling that this will somehow do a disservice to me and my memory? I may not deserve all the consideration due to a human being, but I also don't deserve to be treated like a toaster oven: i.e., something that can simply be replaced with a functional equivalent when it ceases to operate. If this is in fact how you view me, then these critics who charge you with being overly sentimental couldn't be further from the truth!

My suspicion is that many of you will be somewhat skeptical of this line of argument, but your skepticism probably arises in large part because I have put it into the mouth of a canine. "Missy is just a dog," one might object, "and while the kind of treatment she is demanding does seem appropriate for a 
person, it isn't so clear that it is appropriate for an animal that lacks the capacity to reason or (despite the fictional tirade) use language. Perhaps dogs are in fact closer to toaster ovens than they are to human beings. At any rate, we need to be shown why this isn't the case."

I think this is an objection that can be met, but I won't pursue that project here. ${ }^{2}$ For now what is important is that the objection grants that Missy's tirade is the kind of thing that it does make sense for a person to say-the vision of love and attachment sketched by Missy is one we can understand and endorse as applying to persons if not also applying to animals. This is, for my present purposes, enough.

\title{
THE PUZZLE
}

Several philosophers have commented on the apparently strange fact that in loving another person we tend to value the other in a way that goes beyond simply valuing the characteristics that compose the person.

\begin{abstract}
Apparently, love is an interesting instance of another relationship that is historical, in that (like justice) it depends upon what actually occurred. An adult may come to love another because of the other's characteristics; but it is the other person, and not the characteristics, that is loved. The love is not transferable to someone else with the same characteristics, even to one who "scores" higher for these characteristics. And the love endures through changes of the characteristics that gave rise to it. One loves the particular person one actually encountered. Why love is histori$\mathrm{cal}$, attaching to persons in this way and not to characteristics, is an interesting and puzzling question. ${ }^{3}$
\end{abstract}

The unique value we attribute to the beloved cannot be captured by a reductive analysis of the value of the properties that make up that person. In addition, we are hesitant to "swap" a loved one for another who possesses identical properties or even superior properties. The beloved is, in an important sense, irreplaceable.

This point seems, to many, to be reasonable enough, but there is a long and impressive philosophical tradition that challenges the reasonableness of this sort of attachment. The challenges come in several forms. Some thinkers argue that we can't possibly be attaching to what we think we are because persons are not what we think. Others argue that regardless of what we are attaching to, we ought to attach differently: philosophical reflection shows us that we ought to revise our practice. I want to spend some time considering the views of those skeptical about irreplaceability in order to better understand why this kind of value - this kind of attachment - seems suspect to many. I think this will ultimately help us get clearer on just what it means to 
value someone or something as irreplaceable, and that will put us in a better position to classify this kind of value and see how it relates to some of the other categories of value that philosophers have discussed.

\section{PLATO}

Perhaps the earliest philosophical argument that loving another is best understood as loving qualities or characteristics of the other is to be found in the writings of Plato. In the Symposium, Socrates finds himself in a contest with his friends to give a speech on the nature of love. Prior to Socrates's speech, Aristophanes tells a mythical tale of the origin of the human race. According to this tale, there were originally three races, not two. People were doubled-up, in a sense: they were round — with four arms, four legs, and two faces. There was a female race, a male race, and one in which an individual shared both sexes. The story goes that these "globular" early humans were incredibly strong and proud, and they eventually attempted to "assault the gods" (190C). ${ }^{4}$ As punishment, Zeus decided to split each of them into two, right down the middle, and this resulted in humans coming to take their present form. According to Aristophanes, then, love is quite literally a search for our "other half" - a desire to be reunited with the other human with whom one was once coupled.

When it is Socrates's turn to speak, he offers a speech that he says was given to him by the priestess Diotima. In that speech Diotima argues against accounts like Aristophanes's:
"And there is a certain account," she said, "according to which those who seek their own halves are lovers. But my speech denies that eros is of a half or of a whole-unless, comrade, that half or whole can be presumed to be really good; for human beings are willing to have their own hands and feet cut off, if their opinion is that their own are no good. For I suspect that each does not cleave to his own (unless one calls the good one's own and belong- ing to oneself, and the bad alien to oneself) since there is nothing that human beings love other than the good." (205E)

The claim here seems to be that other people are valued not in themselves or for their own sake but for the sake of the good they manifest. In loving another we don't actually seek out our "better half"-we seek those good qualities that make our "better half" better. It should be understood that the "good" was a term with a very broad connotation for the Greeks, however, and in addition Diotima and Socrates appear to allow that many people can have deeply misguided conceptions of what is, in fact, good. Nonetheless, the important point for our purposes is that however the good is construed, $i t$ is 
what we are actually valuing when we love someone. (If the goodness was absent, the love would presumably be extinguished.)

Diotima's claim that humans love only the good is supplemented by a prescription for the course that proper love must take: one begins by loving a beautiful body (for eros naturally pursues the good through the beautiful [206B-C]), but one then eventually realizes that this beauty can be found elsewhere in similarly attractive persons. This realization brings with it a slackening of attachment to any one body, and allows the lover to pursue beauty wherever he can find it. After this, one should come to believe that "beauty in souls is more honorable than that in the body" and similarly realize that this beauty is also generalizable and should be appreciated wherever it is found. Finally, one comes to see the beauty of sciences and ultimately conclude that the most beautiful and thus lovable thing is the idea of good itself (210A-D). To love properly, on this account, is to follow a path from loving a particular individual because he is beautiful (and thus good) to coming to love the good directly.

To summarize, people are desirable and lovable because they contain reflections of the idea of the good, and upon realizing this one can cut out the "middleman" by cutting out the "man" altogether and going on to love the good directly. In fact, on the scale one must climb to reach the good, persons are toward the bottom, for love of them is viewed (by Plato) as less valuable than love for impersonal abstractions, as scholars such as Gregory Vlastos and Martha Nussbaum have emphasized in their writings on this topic. ${ }^{5}$

While it is difficult to know exactly to what extent Plato wanted to endorse the account of love offered by Diotima, it appears to fit well with claims that Socrates makes regarding love in other dialogues (such as the Phaedrus) and it also seems to cohere with his more general claims about the importance of the good. A more difficult problem is determining to what extent this account of love is being offered as a descriptive rather than a revisionary account. It seems to include elements of both: Diotima gets Socrates to agree that "there is nothing that human beings love other than the good" is a true description of the manner in which eros functions (with the acknowledgment that often humans fail to perceive the good correctly). Diotima then goes on to instruct Socrates in the proper path that love ought to take-one ought to pursue what is truly good, and ultimately one ought to pursue it as directly as possible.

Though few people in fact pursue the good in the manner prescribed by Diotima, the thought is that we all ought to strive to follow this path toward unmediated loving of the pure good. Both the lover of a pretty body and the more enlightened lover of the idea of the good seem to share one thing in common from the get-go; however: neither love people in a way that is independent of loving the good manifested in the person. People are, on this 
account, simply repositories for the good and beautiful, and to this extent ultimately replaceable with others who manifest beauty and goodness to an equal or greater degree. Vlastos has argued that this is a serious flaw in Plato's account:

We are to love persons so far, and only insofar, as they are good and beautiful. Now since all too few human beings are masterworks of excellence, and not even the best of those we have the chance to love are wholly free of the streaks of the ugly, the mean, the commonplace, the ridiculous, if our love for them is to be only for their virtue and beauty, the individual, in the uniqueness and integrity of his or her individuality, will never be the object of our love. This seems to me the cardinal flaw in Plato's theory. It does not provide for love of whole persons, but only for love of that abstract version of persons which consists of the complex of their best qualities. ${ }^{6}$

Plato has given us an account of the love of persons that can't help but strike many readers as disturbing. While Aristophanes's myth may well be nothing more than a romantic fantasy, it does seem to capture something crucial that Diotima's account does not: it recognizes our deeply felt need to value the beloved as a unique individual. Plato's prescription for abstraction fails entirely to account for or make sense of this need.

Though the impersonal nature of Plato's account of personal love inclines many to reject it as erroneous, even his critics acknowledge that this vision of love is motivated by a powerful idea. Most of us would be inclined to agree with Plato that if anything is an intrinsically valuable and an unproblematically justifiable thing to desire and pursue, it is goodness. The notion of persons as possessing some other sort of value can, without much philosophical prompting, easily come to seem rather mysterious, but it is not difficult to appreciate that persons can be straightforwardly valued as creatures that manifest the good in various ways. In explaining our attachment to the other in terms of an attachment to the good, Plato's account offers us a way of conceptualizing our love of persons as something reasonable rather than irrational: our love for the other is a natural though inefficient way for human beings to pursue the good.

So I think most of us can sympathize, at least in part, with Plato's motivations here. However, most also agree with Vlastos when he complains that Plato's account seems to miss the mark-it leaves out something we care about, namely the person, even if it does provide a rationale for what can seem to be a rather irrational attachment. I want to now look briefly at another thinker who suspected that there is something dubious going on when we talk of loving individual persons. 


\section{PASCAL}

Many years after Plato, Pascal wrote the following in his Pensees:

What is the self? A man goes to the window to see the people passing by; if I pass by, can I say he went there to see me? No, for he is not thinking of me in particular. But what about a person who loves someone for the sake of her beauty; does he love her? No, for smallpox, which will destroy beauty without destroying the person, will put an end to his love for her. And if someone loves me for my judgment or my memory, do they love me? me, myself? No, for I could lose these qualities without losing my self. Where then is this self, if it is neither in the body nor the soul? And how can one love the body or the soul except for the sake of such qualities, which are not what makes up the self, since they are perishable? Would we love the substance of a person's soul, in the abstract, whatever qualities might be in it? That is not possible, and it would be wrong. Therefore we never love anyone, but only qualities. ${ }^{7}$

Pascal doesn't insist with Plato that we must actually be loving the apparently good or beautiful qualities of a person, but he does seem forced to conclude that at bottom what we must be loving are qualities of some sort or another. Pascal is more explicit than Plato regarding just why he comes to this conclusion, and with his help we begin to get a better sense of just why Nozick's "puzzling" question about the nature of love is so puzzling. While our natural inclination is to think that our love for a person is not just a love for the characteristics of the person, Pascal challenges us to imagine in what else it could coherently consist. The thought of loving a self independently of any characteristics or properties of that self seems ludicrous. What kind of love could that possibly be? If it is even possible to conceptualize a self free of qualities, why on earth should anyone find anything lovable in that? Our initial thought that love for another transcends properties comes to seem not just confused, but ridiculous.

Pascal also points out that his diagnosis (that love must be for qualities) corresponds with our own experience regarding the limits of love:

He no longer loves the person he loved ten years ago. I quite believe it: she is not the same any more, nor is he. He was young and so was she; now she is quite different. Perhaps he would still love her as she used to be then. ${ }^{8}$

When enough of the characteristics of a person change, our love also tends to change or fade. Doesn't this show, as well as anything could, that what we were actually attached to were those characteristics? 
We aren't sure how else to explain our love except in terms of the qualities possessed by the beloved, and similarly when we introspect and consider what is lovable about ourselves, we are also inclined to explain our own worth in terms of various properties we possess. To claim to love another for reasons removed from the other's characteristics seems absurd; to be told one is being loved in a way divorced from one's qualities perplexing.

\section{THE SWAP}

Pascal's points have force, for it isn't initially obvious what else could qualify as a coherent object of our love other than the collection of properties that make up a person. Nevertheless, perhaps caution is in order here. While it is an open question just what we ought to love when we love a person, Pascal's claim that "we never love anyone" seems too strong. Regardless of what it might make the most sense to love, many of us certainly think we are loving other persons, and loving them in a way that transcends an appreciation of their properties. This remains true even if we haven't the foggiest notion how to make sense of such an attachment. That this is so can be seen with the help of a somewhat far-fetched but nonetheless revealing thought-experiment:

Imagine that it is possible to replace a person with another who is exactly similar. It does not seem likely that such a procedure is physically possible, but for the sake of argument imagine that we are capable of producing an exact physical and psychological duplicate of a person. Now, imagine that a friend you love deeply is going to be transferred to another planet exactly similar to our own (a la Twin Earth) to pursue the same life-plan she has pursued here on Earth, and with presumably the same degree of success. You, however, will never again have contact with her. Instead you will find yourself encountering an exact duplicate who will be placed on Earth to resume your original friend's job and other responsibilities. The duplicate who replaces your friend is not simply a clone with the same genetic makeup - it is an exact replica of your friend, and one who has been created just prior to the switch. Upon being told that a close friend will be, for whatever reason, replaced by such a duplicate, most of us would find this "swap" disturbing. Something valuable (to you) would seem to be lost in the exchange. ${ }^{9}$

What are we to make of our reaction to this sort of case? At the very least, it seems to cast doubt on Pascal's assertion that all we ever really care about are qualities. After all, the duplicate will share all of my friend's qualities, and my sense of loss seems to be fully compatible with an appreciation of this fact. If one still has doubts that a sense of loss is the appropriate reaction in this kind of case, modify the example such that you are the one who will be replaced while your friend continues to live on with a duplicate of 
you. How ought your friend react to the news? A lack of concern on the part of your friend would seem to be a kind of insult, and would raise the suspicion that you were not really being loved to begin with. Whether it is rational or reasonable, we do often love persons in a manner that can't simply be reduced to a love of the qualities that persons possess, and in addition we expect (or at least hope) to be loved in a similar manner. Accordingly, loved ones are valued as irreplaceable in a way that Pascal's account can't acknowledge. Even if it is true that we ought to only love qualities, it can't be quite right that that is all we do love. ${ }^{10}$ The truth seems closer to the view once stated by McTaggart, which, though as forcefully blunt as Pascal's, is otherwise diametrically opposed: "Love is for the person, and not for his qualities, nor is it for him in respect of his qualities. It is for him." 11

\section{UNIQUE VALUE}

I'm going to refer to the value we accord to something when we are reluctant to accept a substitution (even an exactly similar substitution) as "unique value." (In other words, unique value is the value we attribute to something when we take it to be irreplaceable in the manner I've just discussed.) Now, as the swap thought experiment is supposed to show, this unique value that comes with being irreplaceable ought not to be understood as based on the contingent fact that there is no one else around at the moment who shares all of one's qualities, nor should it be seen to be based on the mistaken belief that such a duplicate is impossible in theory. That the unique value that we accord to those we care about does not necessarily "hinge" on any such thesis is made evident when we consider the fact that upon being convinced that such a duplication would be possible in theory (or even in fact) it still seems perfectly plausible for one's attitude regarding the unique value of persons to remain entirely unchanged.

The kind of uniqueness or individuality at issue here is not the sort of thing that could be "hostage to fortune" by being dependent on a possible empirical discovery (to use a nice phrase employed by David Cockburn when he talks about this topic). ${ }^{12}$ Harry Frankfurt also makes this kind of point, and he discusses an example where he encounters an exact duplicate of his daughter. He's not sure what his response would be, but it certainly wouldn't involve the conclusion that he has somehow been wrong to love her the way he did because he mistakenly supposed there was no one quite like her around. ${ }^{13}$

It appears that whatever we mean by unique value, we must mean something other than that kind of "matter of fact" uniqueness. One thing we could mean is simply that we value the beloved uniquely - we value her in a way 
that embodies the attitude that she is an individual and thus unique, incomparable, and irreplaceable. This attitude is not based on any belief about uniqueness of qualities (in fact or in theory) that could turn out to be falseit is independent of that kind of consideration. ${ }^{14}$

\section{METAPHYSICAL VS. NORMATIVE WORRIES}

Even after we've gotten clearer on just what kind of attachment is involved in valuing another as irreplaceable, I think the worry still remains for many that there is something metaphysically incoherent lurking in our thought on this matter. As Pascal's comments hint, it appears we face a metaphysical dilemma in trying to make sense of our attachment. The worry is that we can't possibly be valuing persons in the way we pre-reflectively think we are: either we are attaching to a featureless soul (or a bare locus or substratum of some sort) or we are attaching to a collection of properties which could, in theory, be repeated in another.

This type of worry is a very natural and pervasive one; if we adopt a model of the person in which people are taken to be metaphysically bare loci, or mysterious and imperceptible substrates, then it would appear that only God (if anyone) could value such creatures. No doubt some have been driven to such a view by the thought that the only alternative is the view that persons are "nothing but properties," and thus it must be the abstract properties that we love and value. Our initial (seemingly innocent) thought that we attach to an irreplaceable individual comes to appear metaphysically suspect.

If this metaphysical worry is the motivation of skeptics of irreplaceability, I want to argue that it is misguided for reasons that Saul Kripke has offered in Naming and Necessity.

What I do deny is that a particular is nothing but a 'bundle of qual-
ities', whatever that may mean. If a quality is an abstract object, a
bundle of qualities is an object of an even greater degree of
abstraction, not a particular. Philosophers have come to the
opposite view through a false dilemma: they have asked, are these
objects behind the bundle of qualities, or is the object nothing
but the bundle? Neither is the case; this table is wooden, brown,
in the room, etc. It has all these properties and is not a thing
without properties, behind them; but it should not therefore be
identified with the set, or 'bundle', or its properties, nor with the
subset of its essential properties.

A particular person, like any particular object, is correctly understood as something that possesses properties without "lurking behind" those properties in a problematic manner.

Now, I don't want to deny that there are many interesting metaphysical questions and problems here. All I want to do is point out that there isn't a 
special metaphysical problem regarding the object of our attachment when we love someone or value something as irreplaceable. I think sometimes people think there is a special problem because they get into a kind of type/token confusion: when thinking about the reasonableness of our attachment, they feel forced to conclude that we must be valuing an abstraction (a type-a collection of qualities) because the only alternative appears to be that we are valuing something devoid of properties altogether. The truth is that we are not valuing a type but a particular token (the individual person-where that person is best understood as not being a featureless metaphysical mystery but as made up of a particular instantiation of qualities/properties).

Of course some will point out (rightly, I think) that this clears up a metaphysical/ontological puzzle only to replace it with a normative puzzle about the rationality of our attachment: why on earth should we attach to the particular instantiation rather than the abstract properties themselves? How can it be reasonable to be so partial in our valuation? It is natural to think that we must have some reasons for our attachment, and since reasons are by their nature general such reasons would presumably refer to those qualities of a person that could, at least theoretically, be repeated in another. ${ }^{16}$ In other words, it would seem that in order for my attachment to the beloved to be rational, there must be some rationale- there must be reasons like "I like her yellow hair, I like her sense of humor, etc."-but these reasons, if they are genuine, must apply to similar cases - they must generalize.

This is indeed a real puzzle, and one that I explore elsewhere. ${ }^{17}$ (I defend the view that there are ways in which our attachment is in part unreasoned and nonrational but not irrational.) For now it will have to suffice to say that this is a conceptually available option. ${ }^{18}$ We can have a legitimate concern over the object of our love without embracing metaphysical mysteries, and once we see this we need not follow Pascal or more contemporary skeptics in denying that the focus of love is an individual.

\section{THE VARIETIES OF UNIQUE VALUE}

Love's birth may be based, in part, on the particular qualities of the beloved, but love's bond is best understood not as a bond to those qualities, but to the beloved. Whether it is reasonable or not, many of us attach to particular individuals in a manner that is at least somewhat independent of the qualities that draw us to the person in question.

As my introductory comments about Missy suggest, we don't value only people as irreplaceable individuals: animals also can be valued in this manner. In addition, there are many objects that are valued as irreplaceable in the manner I've considered. In other words, there are objects that we attach to such that we are reluctant to accept a substitute, even when that substitute is 
an exact qualitative duplicate. One example of this would be a great painting, like the Mona Lisa. Most of us would resist a substitute here, and I don't think this resistance is simply based on a fear that the duplicate would somehow fall short or fail to mimic the aesthetic properties of the original adequately. We want the real deal.

In the example of the Mona Lisa I think our attachment to the original is intimately connected to an acknowledgment that the original has a particular history that links it to the original artist, while a duplicate lacks this history. Elsewhere I explore why it is reasonable (i.e., not irrational) to care about this history, but here I'm instead going to take it as a given that we do care about the history-we do grant unique value to persons, animals, and objects-we value them as irreplaceable in the manner I've been considering. For the rest of this essay I want to explore the nature of this value.

\section{UNIQUE VALUE AND INTRINSIC VALUE}

I have been arguing that irreplaceable people and objects possess a kind of noninstrumental value that is, in fact, revealed in our treatment of them as irreplaceable. This is what I'm calling "unique value." Traditionally, intrinsic value has been opposed to instrumental value, and it is accordingly tempting to see a connection between intrinsic value and irreplaceability (or unique value). Christopher Gowans assumes such a connection when he refers to irreplaceable people as possessing "unique and intrinsic value" and claims that "a person is not only intrinsically valuable, but has an intrinsic value which is different from that of everyone else." 19 I now want to explore this supposed connection between irreplaceability and intrinsic value.

G. E. Moore's writings on intrinsic value remain influential, so perhaps it is best to start with him. In his essay "The Conception of Intrinsic Value," he wrote:

To say that a kind of value is "intrinsic" means merely that the question whether a thing possesses it, and in what degree it possesses it, depends solely on the intrinsic nature of the thing in question. $^{20}$

In other words, if an object possesses intrinsic value, it does so in virtue of its intrinsic properties. (To use contemporary jargon, such value supervenes on the intrinsic properties of the object.) An intrinsically valuable object, on this view, cannot derive its intrinsic value from nonintrinsic or relational properties. It follows from this account that any two objects with the same intrinsic properties (in the same degree) will accordingly possess the same intrinsic value: 
if a given thing possesses any kind of intrinsic value in a certain degree, then not only must the same thing possess it, under all circumstances, in the same degree, but also anything exactly like it, must, under all circumstances, possess it in exactly the same degree. ${ }^{21}$

Moore says more about intrinsic value, and some of what he says is very controversial and murky, so for now let's stick with what I'll call his "minimal requirement": intrinsic value supervenes on intrinsic properties. It is pretty clear that this is being offered as a necessary (though not sufficient) condition. To say that something has intrinsic value is to say at least that it has a value which supervenes on its intrinsic properties.

I have earlier argued that to claim a person (or thing) is irreplaceable and thus uniquely valuable is to deny that a duplicate with the same intrinsic properties would possess the same unique value, so if there is a connection between unique value and intrinsic value it can't simply be the fact that unique value just is a species or kind of intrinsic value. Clearly unique value does not meet Moore's minimal requirement for intrinsic value: My duplicate and I have the same intrinsic nature (so if we possess intrinsic value at all, we must possess the same intrinsic value, according to Moore-we can't possess different intrinsic value if our intrinsic properties don't differ), yet we obviously differ in what I'm calling unique value.

What is going on here? Though the temptation to see unique value as a species of intrinsic value has numerous sources, I suspect one reason lay in the tendency of many philosophers to run together the notion of intrinsic value with the distinct notion of valuing someone (or something) as an end (or as a final good). Frankena's standard introductory text Ethics is just one example of a text in which this confusion occurs:

One may also say that something is good on the ground that it is a means, necessary, sufficient, or both, to a good end [...] Then it is extrinsically or instrumentally good, or good as a means. [...] We also sometimes say that things are good, desirable, or worthwhile in themselves, as ends, intrinsically. ${ }^{22}$

This is a mistake that, thankfully, has been corrected recently in the literature by numerous philosophers. Frankfurt, for instance, criticizes Moore for the same kind of slip:

Moore speaks in one breath of "goods or ends in themselves." As though the notion of something being good in itself were freely interchangeable with the notion of its being an end it itself. It seems to me that this aspect of his formulation is out of focus. Whether or not something is good in itself depends exclusively on its inherent characteristics. On the other hand, whether it is an end in itself depends upon whether someone adopts it or pursues it. ${ }^{23}$ 
This conflation has been tempting because the two do often go together: when I value something intrinsically I also often value it as an end. That they can come apart, however, should be clear. As Korsgaard points out in her essay "Two Distinctions in Goodness," the proper contrast with intrinsic value is not instrumental value but extrinsic value, i.e., value deriving from outside the object (through relations with other things). ${ }^{24}$ Once we understand this, we can see how something could be taken to be extrinsically valuable and yet valued as an end. This is relevant because at least some cases of unique value and irreplaceability seem to fit this mold. Consider the example of a crude drawing given by a child: it seems quite plausible to say that the drawing might possess little or no intrinsic value, and yet I might nonetheless value it in a noninstrumental manner (as an end or a "final good" if you don't like the term "end" referring to objects) and take it to be irreplaceable.

It appears, then, that the notion that we should be investigating is not that of intrinsic value but rather that of valuing something as an end. Following Wlodek Rabinowicz and Toni Rønnow-Rasmussen, I'm going to call this sort of value, "final value" to distinguish it from instrumental value or value as a means. ${ }^{25}$ (Frankfurt calls it "terminal value" but that term strikes me as unnecessarily morbid.)

Before I go on to say more about unique value and final value, there is one clarification that is important: many of the same philosophers who have pointed out the danger of conflating intrinsic value with final value have also pointed out that the contrast between valuing something as an end and as a means is not exclusive. Something might possess both instrumental value and be valued as an end: Kagan claims that the pen Abraham Lincoln used to sign the Emancipation Proclamation could be such an object, ${ }^{26}$ Frankfurt suggests that an "invigorating workout" (with its "zestful glow of unimpeded vitality") is a candidate for both sorts of value, ${ }^{27}$ while Korsgaard suggests that a "mink coat" be seen as a case of "mixed" value. ${ }^{28}$ The distinction is genuine, but not exclusive.

While it seemed a mistake to view unique value as a species of intrinsic value, it isn't so obviously mistaken to consider things valued as irreplaceable as a subclass of the larger class of things valued as ends (things with final value). One thing we might mean when we refer to something as being valuable "for its own sake" or "as an end" is that it is irreplaceable to us. That is not always what we mean, however: many things that could be said to have final value are not irreplaceable. Korsgaard at one point talks of an ornately decorated frying pan possessing final value: while I think we can imagine situations in which the pan is valued as irreplaceable (e.g., when it has been given as a gift by a loved one), we can also imagine other cases in which that particular pan could easily be replaced by a similarly ornate pan.

So it seems there are at least two distinct ways in which one might value something as an end. Though I am not entirely confident that the notion of 
"intrinsic value" can be made out in a way that is fully coherent, if we stick to Moore's minimal condition (supervenience on intrinsic properties) one might be inclined to think that the two ways of valuing ends can be divided into valuing something as an end because it is intrinsically valuable (i.e., any duplicate will possess the same intrinsic value and the same value as a final end) or valuing something as an end because it is uniquely valuable and thus irreplaceable. (Another way of putting this: when we value something as an end, we might be valuing that token as an individual or we might be valuing the type of which that token is an example. And when we are valuing the type as an end it is in virtue of its intrinsic properties.)

This distinction, like the one between instrumental value and the value of final ends, is tricky because it is not exclusive: the beautiful painting by Picasso is undoubtedly valued as a final end both because of its intrinsic properties and because of the extrinsic historical properties that ground its unique value.

Also, this contrast should not be taken to have the implication that all nonintrinsic value is thus uniquely valuable (in other words, unique value doesn't just mean extrinsic value): objects might well be valued extrinsically, for their relational properties, and yet be utterly replaceable and not plausibly considered candidates for final value (e.g., a dollar bill).

So it looks like unique value, far from being a kind of intrinsic value, is instead better regarded as a class of final value, the other class consisting of objects valued as ends based on their intrinsic properties. This initially promising account of unique value and its relationship to intrinsic value is incorrect, however. I said we can carve up final value into two classes: things valued as ends based on intrinsic value, and things valued as ends based on unique value. I think that much is right if all we mean by "unique value" is final value based on extrinsic properties. Then my thesis is straightforwardly true, but rather uninteresting. From the beginning, however, I've tied my notion of unique value to the idea that something with unique value is irreplaceable. So, if what we mean by "unique value" is the value we attribute to irreplaceable objects in virtue of their irreplaceability, then the way I just carved things up is interesting but false. Here's why: one can value something on the basis of its nonintrinsic properties and value it as an end, and yet still be valuing it as a type (and thus replaceable by other objects of the same type). In other words, valuing something as an end based on extrinsic properties is not equivalent to valuing something as irreplaceable. Extrinsically grounded final value doesn't equal unique value.

Consider the set of guitars owned by Jimi Hendrix. One might care about a particular guitar (the one played at Woodstock, for example) but then again one might not. One might instead value the entire set of guitars he played, and freely accept a substitute of one guitar for another. (This is a case where history matters, but several objects share the relevant history.) The 
swap thought experiment alone won't tell us what someone is valuing in this kind of situation, as the newly created duplicate fails on both counts-it isn't the right token, and it isn't part of the valued type, so both the lover of the particular guitar and the lover of the set will reject the new duplicate.

Or consider a diamond ring that was not a gift. Many are not inclined to accept the artificial duplicate, but this isn't because they won't accept any substitution, it is rather because the duplicate isn't a member of the valued class. (This is a case where the origin of the object matters-the duplicate lacks the proper natural origin, but many other diamonds have the proper origin and would be acceptable substitutes.)

In fact, I suspect there are quite a few cases, then, where an object can have final value based on extrinsic features yet not be irreplaceable. My initial taxonomy was too crude.

So what, then, is my thesis? Well, now, it isn't quite so tidy, but I still think it is interesting. This much remains true: Contrary to Gowan's claim, unique value is best conceived of as a kind of extrinsic final value, not a type of intrinsic value. Valuing something as irreplaceable (as possessing unique value) involves a kind of final value that derives from certain extrinsic or relational properties of the object. Unique value isn't the only sort of final value that derives from extrinsic properties, however: in cases in which more than one thing can share the relevant extrinsic properties, there can be objects with final value grounded in extrinsic properties that are still replaceable by other objects from the relevant class. (Remember again Hendrix's guitars. Other examples would include the first print-run of a book or perhaps the set of Redwoods.)

I'm reserving the term "unique value" for those objects that have relevant extrinsic properties that are not shared by another (like the guitar Hendrix played at Woodstock [assuming he played just one guitar]). Of course, one person's type is another's token-if you want to consider the class or set of guitars as an individual unit, then you could say that it is what has unique value and is irreplaceable. Say what you like, so long as we keep in mind that this sort of case is distinct from the case where multiple entities are replaceable with one another because they have the same relevant extrinsic properties.

In conclusion, then, I've tried to show that those philosophers who distinguished between intrinsic value and final value didn't quite go far enough. I've argued that there are even more distinctions worth noticing here, and I think that in general these further distinctions have been overlooked because the whole category of unique value has, for the most part, been overlooked.

Before ending, some comments regarding the unique value of persons are in order, since I spent quite a bit of time early on talking about irreplaceable people. I just said that unique value is a kind of final value reserved for those things that have particular extrinsic properties that cannot be shared 
by another. In the case of being in love with another person and valuing them as irreplaceable, I want to argue that it is the particular shared history between the lover and the beloved that plays this individuating role, and thus helps to make the lovers truly irreplaceable to each other. No one else can have that shared history, and accordingly no one else can take the place of the beloved. Further, I think that much of the importance we place on shared history can be illuminated through a focus on the role that shared agency plays in a relationship. This history of agency that two intimates come to share over time distinguishes each partner while at the same time bonding the couple together, and a consideration of the individuating aspects of responsible agency helps us (at least in part) to understand why the possibility of a substitution or swap comes to look perverse. ${ }^{29}$ Now, giving a full account of the relevance of history and the importance of agency for the unique value of persons (and animals and objects) is a large project that cannot be undertaken here. I hope, though, that here I've at least cleared some ground, so that we can better understand the (dare I say "unique"?) nature of what I'm calling unique value, and thus better appreciate how this kind of value both resembles and differs from the other sorts of value that philosophers have traditionally concerned themselves with.

\section{NOTES}

I have benefited from discussion with audiences at Columbia University, Florida International University, and Vassar College. I also received helpful feedback at a session of the 2005 Pacific Division meeting of the American Philosophical Association in which I presented an excerpt from this essay. I owe particular thanks to my commentator at that session, William Tolhurst. In addition, I want to thank Paul Draper, John M. Fischer, Sharon Kaye, S. Matthew Liao, Wlodek Rabinowicz, Toni Rønnow-Rasmussen, Susan Watson, and Susan Wolf for comments on earlier drafts of this essay.

1. More information can be found at www.missyplicity.com.

2. I do attempt to meet this objection in my dissertation: Christopher Grau, The Irreplaceability of Persons, Ph.D. Thesis Johns Hopkins University, 2002. (ProQuest UMI Number: 3068159.)

3. Robert Nozick, Anarchy, State, and Utopia. (New York: Basic Books, 1974), 167-68. For similar statements, see Neera Kapur Badhwar, "Friends as Ends in Themselves," Philosophy and Phenomenological Research 48 (1987): 1-23; John Martin Fischer, "Responsibility and Manipulation," Journal of Ethics 8 (2004): 145-77; Harry Frankfurt, "On Caring," in Necessity, Volition, and Love (Cambridge: Cambridge University Press, 1998), 155-80; Mark Johnston, "Human Beings," Journal of Philosophy 84 (1987): 59-83; Michael Stocker, "The Schizophrenia of Modern Ethical Theories"” Journal of Philosophy 73 (1989): 453-66; Susan Wolf, "Self-Interest and Interest in Selves," Ethics 96 (1986): 711. All of these authors seem (at least implicitly) to endorse the idea of valuing persons as irreplaceable, and most 
seem to share Nozick's view that the nature of this value is puzzling and needs further exploration.

4. Plato, Symposium, trans. Seth Bernardete (Chicago: University of Chicago Press, 1986). Future citations will refer to section number only.

5. Cf. Gregory Vlastos, "The Individual as Object of Love in Plato," in Platonic Studies (Princeton, N.J.: Princeton University Press, 1973); Martha Nussbaum, "Love and the Individual: Romantic Rightness and Platonic Aspiration," in Love's Knowledge: Essays on Philosophy and Literature (New York: Oxford University Press, 1990), 316-17.

6. Vlastos, "The Individual as Object of Love in Plato," 32.

7. Pascal, Pensees, trans. A. J. Krailsheimer (London: Penguin Books, 1966), n.688. Citations are to fragment number.

8. Ibid., n.673.

9. This sort of "swap" is discussed by Robert Kraut, "Love De Re," Midwest Studies in Philosophy, vol. 10, ed. Peter A. French, Theodore E. Uehling, and Howard K. Wettstein (Minneapolis: University of Minnesota Press, 1986); Mark Bernstein, "Love, Particularity, and Selfhood," Pacific Philosophical Quarterly 77 (1996); and Derek Parfit, Reasons and Persons (New York: Oxford University Press, 1984).

10. In "Friends as Ends in Themselves" (Philosophy and Phenomenological Research 48 [1987]: 1-23), Neera Kapur Badhwar argues that the temptation to contrast loving a person with loving a person's characteristics is a mistake derived from the assumption of a "transcendental metaphysics" of the sort offered by Plato. The type of "swap" thought experiment offered here shows, however, that the distinction between loving a person and loving characteristics can be formulated without recourse to a dubious Platonic metaphysics, and thus the puzzle of our attachment that is dismissed by Badhwar is more resilient than she suggests.

11. John McTaggart, The Nature of Existence (Cambridge: Cambridge University Press, 1927), vol. 2, book 5, ch. x61, sec. 468. (Cited by Martin Warner in "Love, Self, and Plato's Symposium," in Philosophical Quarterly 29 [1979].)

12. cf. David Cockburn, Other Human Beings (New York: Macmillan, 1990), 151.

13. Frankfurt, "On Caring," 169.

14. In his provocative and insightful essay "Love as a Moral Emotion" (Ethics 109 [1999]) David Velleman offers a robustly Kantian interpretation of this attitude. Though his position is defended with great skill, I reject it for reasons similar to those of Daniel Callcut ("Tough Love," Florida Philosophical Review 5:1 [2005]) and Elijah Millgram ("Kantian Crystallization," Ethics 114 [2004]).

15. Saul Kripke, Naming and Necessity (Cambridge, Mass.: Harvard University Press, 1980), 52.

16. This sort of point is nicely made in Kenneth Henley's essay, "The Value of Individuals," Philosophy and Phenomenological Research 37 (1977): 345-52.

17. Grau, The Irreplaceability of Persons.

18. In Fiona Ellis's essay "The Metaphysics of Love: A Paradox Dispelled" (Journal of Value Inquiry 35 [2001]: 247-62), she counters Roger Scruton's theory of erotic love. Along the way, as I understand her, she comes close to saying something like my Kripkean point here, but her formulation is too vague to be sure: "Furthermore, he believes also that his beloved is irreplaceable. Yet these features of his attitude admit of a perfectly sober interpretation: he desires her, and his poetic utterance expresses the sense that she is not simply her properties, and that he does not love her for a delimited set of her properties" (261). I believe her position could be strengthened by the more explicit diagnosis I offer above. She does not go on to discuss what I have called the "normative puzzle" of our attachment.

19. Christopher Gowans, Innocence Lost: An Examination of Inescapable Moral Wrongdoing (Oxford: Oxford University Press, 1994), 123. Recognizing difficulties with this view of unique value, Gowans altered his position in "Intimacy, Freedom, and Unique Value: A 'Kantian' Account of the Irreplaceable and Incomparable Value of Persons" (American 
Philosophical Quarterly 33:1 [1996]). In this later essay he rejects the view that persons possess unique value, arguing instead that their irreplaceability can be adequately explained through reference to their capacities as free and responsible agents. While I think there is much of value in Gowans's account, I argue elsewhere (The Irreplaceability of Persons) that his rejection of unique value is unwarranted.

20. G. E. Moore, Principia Ethica (Cambridge: Cambridge University Press, 1956), 51.

21. Ibid., 50.

22. Ethics (New York: Prentice-Hall, 1973), 81.

23. Harry Frankfurt, "On the Usefulness of Final Ends," in Necessity, Volition, and Love, 86.

24. Christine Korsgaard, "Two Distinctions in Goodness" in Creating the Kingdom of Ends (Cambridge: Cambridge University Press, 1996), 249-74.

25. Wlodek Rabinowicz and Toni Rønnow-Rasmussen, "A Distinction in Value: Intrinsic and for Its Own Sake," Proceedings of the Aristotelian Society 100 (1999): 33-52.

26. Fred Feldman, "Rethinking Intrinsic Value," Journal of Ethics 2 (1998): 277-97.

27. Frankfurt, "On the Usefulness of Final Ends," in Necessity, Volition, and Love, 82-94.

28. Korsgaard, "Two Distinctions in Goodness," in Creating the Kingdom of Ends, 249-74.

29. An important issue here is whether the importance of shared history should be explained solely in terms of the importance of shared agency. Christopher Gowans suggests that it can (see note 19), but in my dissertation I argue that the individuating aspect of agency, though useful and important, cannot (on its own) do justice to the phenomenon in question. Our attachment to others as irreplaceable doesn't neatly correspond with their capacities as agents in the manner we might expect if agency was the sole ground of irreplaceability. In other words, we attach to others in a manner that is at least partly independent of their agency. (Consider, for example, the attachment between a mother and an infant incapable of responsible agency.) I also think something similar is true regarding the irreplaceability of objects and animals like Missy: agency has a role to play here, but it doesn't offer a complete justification of our attributions of unique value. 